\title{
ХИМИЧЕСКИЙ ПРОФИЛЬ И БИОЛОГИЧЕСКАЯ АКТИВНОСТЬ ФЛАВОНОИДОВ И ФЕНИЛПРОПАНОИДОВ NЕPЕТА CATARIA L. (LAMIACEAE), ИНТРОДУЦИРОВАННОГО В ВОСТОЧНОЙ СИБИРИ
}

\author{
() Н.И. Кащенко, Д.Н. Оленников * \\ Институт общей и экспериментальной биологии СО РАН, ул. Сахьяновой, 6 , \\ Улан-Удэ, 670047 (Россия), e-mail: olennikovdn@mail.ru
}

Проведено химическое исследование Nepeta cataria L., интродуцированного в Восточной Сибири (Республика Бурятия, Россия). С применением комплекса хроматографических методов выделено 31 соединение, в том числе впервые для вида хризоэриол, цирсилинеол, изороифолин, тилианин, акацетин-7-O-глюкуронид, линарин, сколимозид, кафтаровая, цикориевая и фазеловая кислоты. В ходе изучения распределения фенольных соединений по органам N. cataria впервые показано, что накопление соединений характеризуется органспецифичностью. Кофеилтартроновая кислота является доминирующим компонентом для листьев $(21,59$ мг/г) и стеблей $(16,70$ мг/Г), розмариновая кислота для корней $(36,93$ мг/г) и цветков $(7,67$ мг/г). Исследование биологической активности сухого экстракта $N$. cataria показало наличие у него противовоспалительных свойств. Впервые выявлена противовоспалительная активность у двух маркерных соединений $N$. cataria - лютеолин-7-O-(6"-глюкуроно)-глюкозида и кофеилтартроновой кислоты, причем эффективность последней была наибольшей.

Ключевые слова: Nepeta cataria L., Lamiaceae, флавоноиды, фенилпропаноиды, кофеилтартроновая кислота, ВЭЖХ, противовоспалительная активность.

\section{Введение}

Nepeta cataria L. - многолетнее растение семейства Lamiaceae, широко распространенное в европейской части России, на юге Западной Сибири и на Дальнем Востоке; в Восточной Сибири данный вид является культивируемым. Основное число химических исследований $N$. cataria относятся к вопросам изучения состава летучих терпенов (эфирного масла) и иридоидов (непеталактонов), являющихся характеристическими компонентами данного растительного вида [1]. Известные сведения о составе фенольных соединений $N$. cataria указывают на присутствие в надземной части фенилпропаноидов, среди которых кофеилтартроновая кислота [2], коричная, $n$-кумаровая, кофейная, феруловая, розмариновая кислоты [3, 4]. Также выявлено присутствие простых производных бензойной кислоты - протокатеховой, ванилиновой и сиреневой кислот [3]. Основной группой флавоноидных соединений являются флавоны, в том числе 8-гидроксицирсилол, изотимусин, цирсимаритин, генкванин [5], апигенин, лютеолин, космосиин, цинарозид, апигенин-7-O-глюкуронид, лютеолин-7-О-глюкуронид, лютеолин-7-O-(6"--глюкуроно)-глюкозид [4], хризин и акацетин [3]. В образцах из Германии выявлено присутствие флавонолов в виде моно-, ди- и триметильных производных кверцетина и кемпферола [3]. Данные о химическом составе N. cataria, культивируемом в России, отсутствуют.

Кащенко Нина Игоревна - младший научный сотрудник лаборатории медико-биологических исследований, кандидат фармацевтических наук, e-mail: ninkk@mail.ru Оленников Даниил Николаевич - ведущий научный сотрудник лаборатории медико-биологических исследований, доктор фармацевтических наук, e-mail: olennikovdn@mail.ru
В результате многочисленных исследований доказана терапевтическая эффективность экстракционных препаратов из $N$. cataria и некоторых индивидуальных соединений из него; установлено наличие антибактериальной, антиоксидантной, цитотоксической, спазмолитической и других видов активности [1]. Несмотря на обширные сведе-

\footnotetext{
* Автор, с которым следует вести переписку.
} 
ния о противовоспалительном действии препаратов из различных видов рода Nepeta L., информация об эффективности $N$. cataria ограничена данными о антиноцицептивных и противовоспалительных свойствах эфирного масла [6]. Учитывая важную роль фенольных соединений в формировании общего фармакологического действия любого средства растительного происхождения, особый интерес представляет изучение влияния основных компонентов фенольной природы из N. cataria на процесс воспаления.

В этой связи цель настоящей работы - изучение химического профиля фенольных соединений N. cataria, интродуцированного в Восточной Сибири, а также определение противовоспалительной активности сухого экстракта и некоторых индивидуальных соединений из него.

\section{Экспериментальная часть}

Растительное сырье. Образцы N. cataria были культивированы в Республике Бурятии на опытных плантациях ИОЭБ СО РАН в 2012-2015 гг. (номер сырья): 15,VII.2012 (А), 30,VI.2013 (Б), 25,VI.2014 (В), 10,VII.2015 (Г). Сбор растительного сырья проводили в фазу массового цветения (июнь - июль).

Общие экспериментальные условия. Для колоночной хроматографии (КХ) применяли силикагель

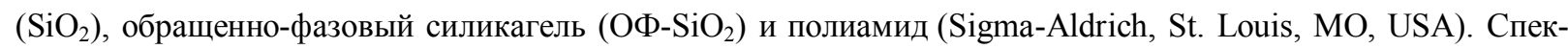
трофотометрические исследования проводили на спектрофотометре СФ-2000 (ОКБ Спектр, СанктПетербург, Россия); МС-анализ - на масс-спектрометре высокого разрешения MAT 8200 (Termo Finnigan LLC, San Jose, CA, USA). Спектры ЯMP регистрировали на ЯMР-спектрометре VXR 500S (Varian, Palo Alto, CA, USA).

Экстракция и фракционирование. Навеску высушенной и измельченной травы N. cataria (420 г) экстрагировали диэтиловым эфиром $\left(\mathrm{Et}_{2} \mathrm{O} ; 1: 10\right)$ при $30{ }^{\circ} \mathrm{C}$ в течение 12 ч трехкратно. Полученное извлечение отфильтровывали и концентрировали в вакууме досуха; получено 4,3 г Еt 2 О-экстракта (фракция Nc-01; 1,0\% от массы возд.-сух. сырья). Фракцию $\mathrm{Nc}-01$ (4 г) разделяли на $\mathrm{SiO}_{2}(\mathrm{KX}, 8 \times 50$ см) в градиентной системе гексан - EtAc (100: 0 $\rightarrow 0: 100)$, что привело к получению подфракций Nc-01/1-Nc-01/10. Подфракции $\mathrm{Nc}-01 / 2, \mathrm{Nc}-01 / 4-\mathrm{Nc}-01 / 6$ хроматографировали на ОФ-SiO 2 (флеш-КХ, $5 \times 40$ см) в градиентной системе $\mathrm{H}_{2} \mathrm{O}-\mathrm{MeCN}(100: 0 \rightarrow 0: 100)$, в результате чего были выделены 1 (0,5 мг), 2 (14 мг), 3 (0,8 мг), 4 (8 мг), 5 (18 мг), 6 (6 мг), 7 (3 мг), 8 (1 мг), 9 (2 мг), 10 (0,5 мг), 11 (1 мг), 12 (0,5 мг), 13 (0,7 мг), 14 (0,4 мг). Из подфракции $\mathrm{Nc}-01 / 2$ после рехроматографии на $\mathrm{SiO}_{2}$ также были выделены урсоловая и олеаноловая кислоты (16 мг) в виде смеси (соотношение соединений, по данным ГХ/MC, 9,5 : 1). Остаток сырья после экстракции $\mathrm{Et}_{2} \mathrm{O}$ обрабатывали 70\% этанолом (1 :20) в УЗ-ванне (100 Вт, частота 35 кГц) при 50 $\mathrm{C}$ в течение 90 мин дважды. Полученное извлечение отфильтровывали и концентрировали в вакууме до водного остатка, который подвергали жидкофазной экстракции этилацетатом и $н$-бутанолом. Получены фракции этилацетатная (Nc-02; 19,7 г, 4,7\%) и н-бутанольная (Nc-03; 60,1 г, 14,3\%). Фракцию Nc-02 (18 г) разделяли на полиамиде $(\mathrm{KX}, 10 \times 50$ см), элюируя последовательно водой (фракция Nc-02/1, 1,67 г), 40\% этанолом (фракция Nc-02/2, 9,37 г), 90\% этанолом (фракция Nc-02/3, 3,47 г) и 0,1\% $\mathrm{NH}_{3}$ в 90\% этаноле (фракция Nc02/4, 2,11 г). Фракцию Nc-02/2-Nc-02/4 разделяли с применением флеш-КХ на $\mathrm{SiO}_{2}(4 \times 50$ см; элюент гексан - EtAc $100: 0 \rightarrow 0: 100)$ и $\mathrm{KX}$ на ОФ-SiO $2\left(2 \times 30\right.$ см; элюент $\left.\mathrm{H}_{2} \mathrm{O}-\mathrm{MeCN} 100: 0 \rightarrow 0: 100\right)$, что привело к выделению 15 (11 мг), 16 (16 мг), 18 (6 мг), 19 (4 мг), 20 (14 мг), 21 (5 мг), 22 (16 мг), 25 (4 мг), 26 (322 мг), 27 (31 мг), 30 (10 мг). Из фракции Nc-03 (20 г) после хроматографического разделения (КХ) на полиамиде, $\mathrm{SiO}_{2}$ и ОФ-SiO, , как описано выше, были выделены 17 (6 мг), 23 (9 мг), 24 (107 мг), 28 (4 мг), 29 (10 мг) и 31 (9 мг).

Тилианин (акацетин-7-O- $\beta$-D-глюкозид; 18). $\mathrm{C}_{22} \mathrm{H}_{22} \mathrm{O}_{10}$, ESI-MS, $m / z: 445$ [M-H]', 283 [(M-Glc)-H]'. ЯМР ${ }^{1} \mathrm{H}(500$ Гц, MеOH-d 4 , $\delta$, м.д.): 8,02 (2H, д, J = 9,0, Н-2', Н-6'), 7,06 (2H, д, J = 9,0, Н-3', Н-5'), 6,91 (1Н, c, H-3), 6,80 (1H, c, H-8), 6,48 (1H, c, H-6), 5,25 (1H, д, J = 7,1, $\left.\mathrm{H}^{\mathrm{Glc}}-1^{\prime \prime}\right), 4,20\left(1 \mathrm{H}\right.$, дд, J = 12,0, 2,0, $\left.\mathrm{H}^{\mathrm{Glc}}-6_{\mathrm{A}}{ }^{\prime \prime}\right)$, $3,98\left(1 \mathrm{H}\right.$, дд, $\left.\mathrm{J}=12,0,5,6, \mathrm{H}^{\mathrm{Glc}}-6_{\mathrm{B}}^{\prime \prime}\right), 3,87\left(3 \mathrm{H}, \mathrm{c}, 4^{\prime}-\mathrm{OCH}_{3}\right), 3,20-3,67\left(4 \mathrm{H}, \mathrm{M}, \mathrm{H}^{\mathrm{Glc}}-2^{\prime \prime}, \mathrm{H}^{\mathrm{Glc}}-3^{\prime \prime}, \mathrm{H}^{\mathrm{Glc}}-4^{\prime \prime}, \mathrm{H}^{\mathrm{Glc}}-5^{\prime \prime}\right)$.

Акацетин-7-О- $\beta$-D-глюкуронид (19). $\mathrm{C}_{22} \mathrm{H}_{20} \mathrm{O}_{11}$, ESI-MS, $m / z$ : 458 [M-H], 283 [(M-GlcA)-H]-. ЯMP ${ }^{1} \mathrm{H}$

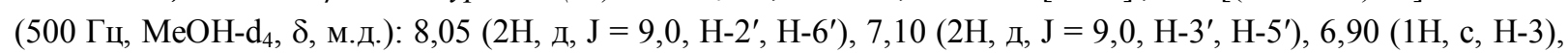
$6,82(1 \mathrm{H}$, д, $\mathrm{J}=2,0, \mathrm{H}-8), 6,47(1 \mathrm{H}$, д, $\mathrm{J}=2,0, \mathrm{H}-6), 5,02\left(1 \mathrm{H}\right.$, д, $\left.\mathrm{J}=8,0, \mathrm{H}^{\mathrm{GlcA}}-1^{\prime \prime}\right), 3,85\left(3 \mathrm{H}, \mathrm{c}, 4^{\prime}-\mathrm{OCH}_{3}\right), 3,62-$ $3,20\left(4 \mathrm{H}, \mathrm{M}, \mathrm{H}^{\mathrm{GlcA}}-2^{\prime \prime}, \mathrm{H}^{\mathrm{GlcA}}-3^{\prime \prime}, \mathrm{H}^{\mathrm{GlcA}}-4^{\prime \prime}, \mathrm{H}^{\mathrm{GlcA}}-5^{\prime \prime}\right)$.

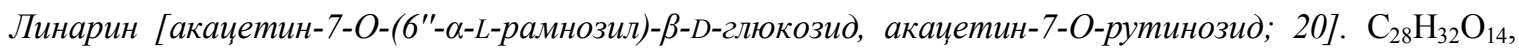

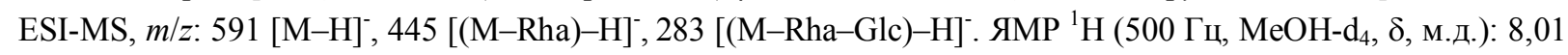
$(2 \mathrm{H}$, д, J = 9,0, Н-2', Н-6'), 7,04 (2H, д, J =9,0, H-3', H-5'), 6,92 (1H, c, H-3), 6,78 (1H, c, H-8), 6,45 (1H, c, Н- 
6), $5,31\left(1 \mathrm{H}\right.$, д, $\left.\mathrm{J}=7,1, \mathrm{H}^{\mathrm{Glc}}-1^{\prime \prime}\right), 4,50\left(1 \mathrm{H}, \mathrm{M}, \mathrm{H}^{\mathrm{Rha}}-1^{\prime \prime \prime}\right), 3,85\left(3 \mathrm{H}, \mathrm{c}, 4^{\prime}-\mathrm{OC} \underline{H}_{3}\right), 3,49\left(1 \mathrm{H}, \mathrm{M}, \mathrm{H}^{\mathrm{Glc}}-6_{\mathrm{A}}{ }^{\prime \prime}\right), 3,45(1 \mathrm{H}$, м, $\left.\mathrm{H}^{\mathrm{Glc}}-6_{\mathrm{B}}{ }^{\prime \prime}\right), 3,18-3,60\left(8 \mathrm{H}, \mathrm{m}, \mathrm{H}^{\mathrm{Glc}}-2^{\prime \prime}-5^{\prime \prime}, \mathrm{H}^{\mathrm{Rha}}-2^{\prime \prime}-5^{\prime \prime}\right), 1,05\left(1 \mathrm{H}\right.$, д, J =6,2, $\left.\mathrm{H}^{\mathrm{Rha}}-6^{\prime \prime \prime}\right)$.

Микроколоночная ВЭЖХ-УФ (МК-ВЭЖХ-УФ). Количественный анализ растительного сырья проводили методом МК-ВЭЖХ-УФ. Для этого 40 мг сырья переносили в пробирку Эппендорф (2 мл), приливали 1 мл 40\% этанола и подвергали ультразвуковой обработке $\left(50\right.$ кГц, 30 мин, $\left.40{ }^{\circ} \mathrm{C}\right)$, после чего центрифугировали $(6000 \mathrm{~g}, 20$ мин). Полученное извлечение фильтровали через мембранный фильтр $(0,45$ мкм) и использовали для анализа (1 мкл). Условия: колонка ProntoSIL-120-5-C18 AQ (2 × 75 мм, Ø 5 мкм; Metrohm $\mathrm{AG})$; подвижная фаза: 0,2 $\mathrm{M} \mathrm{LiClO}_{4}$ в 0,006 $\mathrm{M} \mathrm{HClO}_{4}(\mathrm{~A}), \mathrm{MeCN}(\mathrm{B})$; градиентный режим (\% В): 0-6 мин 5-15\%, 6-10 мин 15\%, 10-16 мин 15-25\%, 16-20 мин 25-90\%; v 150 мкл/мин; температура колонки 35ㄷ; УФ-детектор, $\lambda 324$ нм. Расчет содержания индивидуальных компонентов проводили по градуировочным графикам, построенным с применением коммерческих образцов стандартных соединений (кафтаровая кислота, 3-O-кофеилхинная кислота, кофейная кислота, цикориевая кислота, изороифолин, розмариновая кислота - все Extrasynthese, Lyon, France) и выделенных образцов соединений с чистотой $\geq 95 \%$ [кофеилтартроновая кислота, фазеловая кислота, лютеолин-7-O-(6"'-глюкуроно)-глюкозид, сколимозид, лютеолин7-O-глюкуронид, апигенин-7-O-глюкуронид].

Получение сухих экстрактов. Навеску измельченного растительного сырья (образец Б; 50 г) экстрагировали 0-95\% этанолом (1 : 20) в УЗ-ванне (40 кГц, 60 мин, 40 C) двукратно. Полученные извлечения отфильтровывали и после объединения концентрировали в вакууме до 1/30-1/40 первоначального объема. Концентрированный остаток высушивали в вакуум-сушильном шкафу до значений влажности 4-5\% от массы экстракта и измельчали.

Противовоспалительную активность изучали на модели воспаления уха у мышей с использованием 12-O-тетрадеканоилфорбол ацетата в качестве индуктора воспаления ( $\geq 99 \%$; Sigma-Aldrich) [7]. В paботе использовали растворы соединений в 0,9\% $\mathrm{NaCl}$. В качестве препарата сравнения применяли индометацин ( $\geq$ 99\%; Pfizer, New York, NU, USA), в контрольной группе - 0,9\% NaCl. Результаты выражали в процентах ингибирования отека относительно такового в контрольной группе.

\section{Обсуждение результатов}

Фенольные соединения листьев N. cataria. В результате хроматографического разделения из листьев $N$. cataria выделено 31 соединение, в том числе 24 флавоноида и 7 фенилпропаноидов, строение которых было установлено на основании данных УФ-, ИК-, МС-, ЯМР-спектроскопии (рис. 1). Соединения были идентифицированы как апигенин (1), генкванин (2) [8], акацетин (3), лютеолин (4), хризоэриол (5) [9], ладанеин (6) [10], цирсимаритин (7), сальвингенин (8), цирсилинеол (9) [9], тимусин (10) [11], ксантомикрол (11) [12], гарденин В (12) [13], 8-гидроксицирсилол (13) [5], тимонин (14) [14], космосиин (15), апигенин-7$O$-глюкуронид (16) [15], изороифолин (17) [16], тилианин (18), акацетин-7-O-глюкуронид (19), линарин (20) [17], цинарозид (21), лютеолин-7-O-глюкуронид (22) [4], сколимозид (23) [16], лютеолин-7-O-(6"глюкуроно)-глюкозид (24) [4], кофейная кислота (25), кофеилтартроновая кислота (26) [2], кафтаровая кислота (27), цикориевая кислота (28) [18], фазеловая кислота (29), розмариновая кислота (30) [19] и 3-Oкофеилхинная кислота (31) [20].

Ранее в $N$. cataria установлено наличие компонентов 1-4, 7, 8, 10-16, 21, 22, 24-26, 30, 31 [1-5]; присутствие 10 соединений $(\mathbf{5}, \mathbf{9}, \mathbf{1 7}-\mathbf{2 0}, \mathbf{2 3}, \mathbf{2 7 - 2 9 )}$ выявлено впервые для вида. Следует отметить факт обнаружения гликозидов акацетина $(\mathbf{1 8 - 2 0})$, а также кофеилвинных кислот $(27,28)$ и кофеиляблочной кислоты (29), не описанных ранее для рода Nepeta L. в целом.

Согласно данным ВЭЖХ детектируемые уровни содержания отмечены для 12 соединений, в том числе 5 флавоноидов $(\mathbf{1 6}, \mathbf{1 7}, \mathbf{2 2 - 2 4 )}$ и 7 фенилпропаноидов (25-31), количественное содержание которых было определено в листьях четырех образцов сырья (рис. 2).

Доминирующей группой соединений листьев $N$. cataria были фенилпропаноиды - 16,60-27,47 мг/Г (табл. 1). Основным компонентом являлась кофеилтартроновая кислота (26), концентрация которой достигала 12,38-21,59 мг/г (75-81\% от общего содержания фенилпропаноидов). На долю 0,5-4,4\% от суммы фенилпропаноидов, что составило $0,15-1,18$ мг/г.

Лютеолин-7-O-(6"-глюкуроно)-глюкозид (24) являлся доминирующим флавонгликозидом листьев N. cataria, доля которого - 67-100\% от общего содержания флавоноидов (0,38-8,88 мг/г). Суммарное содержание идентифицированных фенольных соединений в изученных партиях растительного сырья было $25,48-29,20 \mathrm{мг/г.}$ 
<smiles>[R]c1ccc(-c2cc(=O)c3c(O)c([R])c([R])c([R])c3o2)cc1[R]</smiles>

$1 \mathrm{R}_{1}=\mathrm{R}_{3}=\mathrm{R}_{4}=\mathrm{H} ; \mathrm{R}_{2}=\mathrm{R}_{5}=\mathrm{OH}$

$2 \mathrm{R}_{1}=\mathrm{R}_{3}=\mathrm{R}_{4}=\mathrm{H} ; \mathrm{R}_{2}=\mathrm{OCH}_{3} ; \mathrm{R}_{5}=\mathrm{OH}$

$3 \mathrm{R}_{1}=\mathrm{R}_{3}=\mathrm{R}_{4}=\mathrm{H} ; \mathrm{R}_{2}=\mathrm{OH} ; \mathrm{R}_{5}=\mathrm{OCH}_{3}$

$4 \mathrm{R}_{1}=\mathrm{R}_{3}=\mathrm{H} ; \mathrm{R}_{2}=\mathrm{R}_{4}=\mathrm{R}_{5}=\mathrm{OH}$

$5 \mathrm{R}_{1}=\mathrm{R}_{3}=\mathrm{H} ; \mathrm{R}_{2}=\mathrm{R}_{5}=\mathrm{OH}$ : $\mathrm{R}_{4}=\mathrm{OCH}_{3}$

$6 \mathrm{R}_{1}=\mathrm{OH} ; \mathrm{R}_{2}=\mathrm{R}_{5}=\mathrm{OCH}_{3} ; \mathrm{R}_{3}=\mathrm{R}_{4}=\mathrm{H}$<smiles>O=C(O)/C=C/c1ccc(O)c(O)c1</smiles>

25<smiles>CCOC(CC(=O)O)C(=O)O</smiles>

29

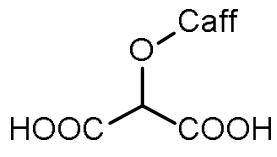

26<smiles>O=C(O)C(Cc1ccc(O)c(O)c1)OC(F)F</smiles>

30
$7 \quad \mathrm{R}_{1}=\mathrm{R}_{2}=\mathrm{OCH}_{3} ; \mathrm{R}_{5}=\mathrm{OH} ; \mathrm{R}_{3}=\mathrm{R}_{4}=\mathrm{H}$

$8 \quad \mathrm{R}_{1}=\mathrm{R}_{2}=\mathrm{R}_{5}=\mathrm{OCH}_{3} ; \mathrm{R}_{3}=\mathrm{R}_{4}=\mathrm{H}$

$9 \mathrm{R}_{1}=\mathrm{R}_{2}=\mathrm{R}_{4}=\mathrm{OCH}_{3} ; \mathrm{R}_{3}=\mathrm{H} ; \mathrm{R}_{5}=\mathrm{OH}$

$10 \mathrm{R}_{1}=\mathrm{R}_{5}=\mathrm{OH} ; \mathrm{R}_{2}=\mathrm{R}_{3}=\mathrm{OCH}_{3} ; \mathrm{R}_{4}=\mathrm{H}$

$11 \mathrm{R}_{1}=\mathrm{R}_{2}=\mathrm{R}_{3}=\mathrm{OCH}_{3} ; \mathrm{R}_{4}=\mathrm{H} ; \mathrm{R}_{5}=\mathrm{OH}$

$12 \mathrm{R}_{1}=\mathrm{R}_{2}=\mathrm{R}_{3}=\mathrm{R}_{5}=\mathrm{OCH}_{3} ; \mathrm{R}_{4}=\mathrm{H}$

$13 \mathrm{R}_{1}=\mathrm{R}_{2}=\mathrm{OCH}_{3} ; \mathrm{R}_{3}=\mathrm{R}_{4}=\mathrm{R}_{5}=\mathrm{OH}$

$14 \mathrm{R}_{1}=\mathrm{R}_{5}=\mathrm{OH} ; \mathrm{R}_{2}=\mathrm{R}_{3}=\mathrm{R}_{4}=\mathrm{OCH}_{3}$

$15 \mathrm{R}_{1}=\mathrm{R}_{3}=\mathrm{R}_{4}=\mathrm{H} ; \mathrm{R}_{2}=O-\beta-\mathrm{D}-\mathrm{Glc} p ; \mathrm{R}_{5}=\mathrm{OH}$

$16 \mathrm{R}_{1}=\mathrm{R}_{3}=\mathrm{R}_{4}=\mathrm{H} ; \mathrm{R}_{2}=O-\beta-\mathrm{D}-\mathrm{Glc} A p ; \mathrm{R}_{5}=\mathrm{OH}$

$17 \mathrm{R}_{1}=\mathrm{R}_{3}=\mathrm{R}_{4}=\mathrm{H} ; \mathrm{R}_{2}=O-\left(6^{\prime \prime}-\alpha-\mathrm{L}-\mathrm{Rh} a p\right)-\beta-\mathrm{D}-\mathrm{Glc} p ; \mathrm{R}_{5}=\mathrm{OH}$

$18 \mathrm{R}_{1}=\mathrm{R}_{3}=\mathrm{R}_{4}=\mathrm{H} ; \mathrm{R}_{2}=O$ - $\beta$-D-Glc $p ; \mathrm{R}_{5}=\mathrm{OCH}_{3}$

$19 \mathrm{R}_{1}=\mathrm{R}_{3}=\mathrm{R}_{4}=\mathrm{H} ; \mathrm{R}_{2}=O-\beta$-D-GlcA $p ; \mathrm{R}_{5}=\mathrm{OCH}_{3}$

$20 \quad \mathrm{R}_{1}=\mathrm{R}_{3}=\mathrm{R}_{4}=\mathrm{H} ; \mathrm{R}_{2}=O-\left(6^{\prime \prime}-\alpha-\mathrm{L}-\mathrm{Rha} p\right)-\beta-\mathrm{D}-\mathrm{Glc} p ; \mathrm{R}_{5}=\mathrm{OCH}_{3}$

$21 \quad \mathrm{R}_{1}=\mathrm{R}_{3}=\mathrm{H} ; \mathrm{R}_{2}=O-\beta-\mathrm{D}-\mathrm{Glc} p ; \mathrm{R}_{4}=\mathrm{R}_{5}=\mathrm{OH}$

$22 \mathrm{R}_{1}=\mathrm{R}_{3}=\mathrm{H} ; \mathrm{R}_{2}=O-\beta$-D-GlcA $p ; \mathrm{R}_{4}=\mathrm{R}_{5}=\mathrm{OH}$

$23 \mathrm{R}_{1}=\mathrm{R}_{3}=\mathrm{H} ; \mathrm{R}_{2}=O-\left(6^{\prime \prime}-\alpha-\mathrm{L}-\mathrm{Rh} p\right)-\beta-\mathrm{D}-\mathrm{Glc} p ; \mathrm{R}_{4}=\mathrm{R}_{5}=\mathrm{OH}$

$24 \mathrm{R}_{1}=\mathrm{R}_{3}=\mathrm{H} ; \mathrm{R}_{2}=O-\left(6^{\prime \prime}-\beta-\mathrm{D}-\mathrm{GlcA} p\right)-\beta-\mathrm{D}-\mathrm{Gl} p ; \mathrm{R}_{4}=\mathrm{R}_{5}=\mathrm{OH}$

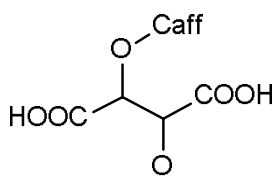

27<smiles>CCOC(C(=O)O)C(O[Ga])C(=O)O</smiles>

28

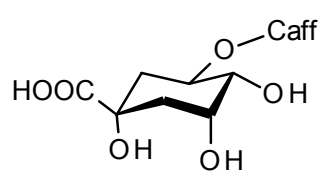

31<smiles>CCC(=O)/C=C/c1ccc(O)c(O)c1</smiles>

Caff

Рис. 1. Структурные формулы соединений, выделенных из N. cataria. Обозначения углеводных остатков: Glcp - глюкопираноза; GlcAp - глюкуронопираноза; Rhap - рамнопираноза

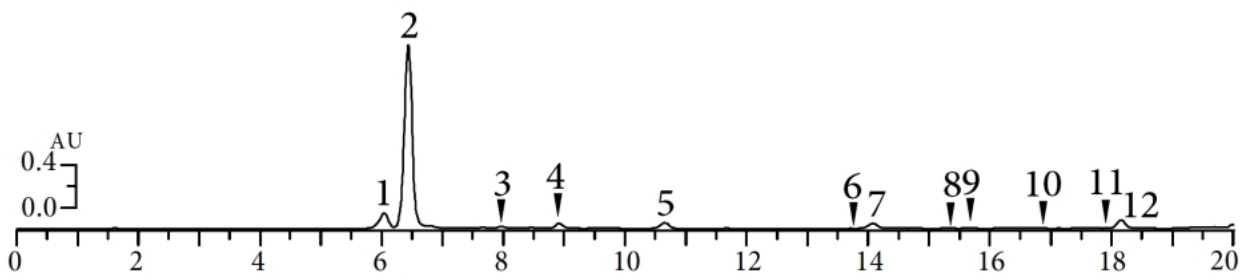

Рис. 2. Хроматограмма (МК-ВЭЖХ-УФ) спиртового экстракта из листьев N. cataria при 324 нм (образец А). Числами обозначено положение соединений: 1 - кафтаровая кислота; 2 - кофеилтартроновая кислота; 3 - 3-O-кофеилхинная кислота; 4 - кофейная кислота; 5 - фазеловая кислота; 6 - цикориевая кислота; 7 - лютеолин-7-O-(6"'-глюкуроно)-глюкозид; 8 - сколимозид; 9 - лютеолин-7-O-глюкуронид; 10 - изороифолин; 11 - апигенин-7-О-глюкуронид; 12 - розмариновая кислота

Фенольные соединения ияветков, стеблей и корней N. cataria. Компонентный состав фенольных соединений других органов $N$. cataria изучали с применением ВЭЖХ, используя в качестве идентификационных критериев время удерживания, данные УФ и МС-спектров в сравнении с таковыми для уже выделенных соединений. Проведенные исследования показали, что химический профиль фенольных соединений цветков и стеблей близок к профилю листьев (рис. 3i, 3ii). Для данных органов выявлена способность к накоплению розмариновой кислоты (30) (7,67-9,39 мг/г) и в меньшей степени - кофеилтартроновой кислоты (26) (4,2316,70 мг/г) (табл. 2). В цветках отмечена бо́льшая концентрация флавоноидов, чем в листьях (4,69 мг/г), причем, в отличие от листьев, доминирующим соединением является лютеолин-7-O-глюкуронид (22). Особенностью корней $N$. cataria является высокое содержание розмариновой кислоты (30) (рис. 3іiі), концентрация которой в исследованном образце составила 36,93 мг/г. Таким образом, можно утверждать, что накопление фенольных соединений в N. cataria характеризуется органспецифичностью. 
Таблица 1. Содержание флавонгликозидов и фенилпропаноидов в листьях N. cataria, мг/г возд.-сух. сырья $( \pm S D)$

\begin{tabular}{|c|c|c|c|c|}
\hline \multirow{2}{*}{ Соединение } & \multicolumn{4}{|c|}{ Номер сырья } \\
\hline & $\mathrm{A}$ & Б & $\mathrm{B}$ & $\Gamma$ \\
\hline \multicolumn{5}{|c|}{ Флавонгликозиды (ФлГ) } \\
\hline Апигенин-7-O-GlcA $p$ (16) & $0,09 \pm 0,00$ & $<0,01$ & $0,24 \pm 0,00$ & $<0,01$ \\
\hline Апигенин-7-O-Rut (17) & $0,28 \pm 0,00$ & $<0,01$ & $<0,01$ & $<0,01$ \\
\hline Лютеолин-7-O-GlcAp (22) & $0,17 \pm 0,00$ & $<0,01$ & $0,36 \pm 0,00$ & $0,35 \pm 0,00$ \\
\hline Лютеолин-7-O-Rut (23) & $0,19 \pm 0,00$ & $<0,01$ & $1,76 \pm 0,04$ & $0,72 \pm 0,01$ \\
\hline Лютеолин-7-O-GlcAp-Glc (24) & $1,48 \pm 0,03$ & $0,38 \pm 0,00$ & $6,52 \pm 0,14$ & $2,63 \pm 0,05$ \\
\hline \multicolumn{5}{|c|}{ Фенилпропаноиды (ФП) } \\
\hline Кофейная кислота (25) & $0,44 \pm 0,00$ & $0,31 \pm 0,00$ & $0,36 \pm 0,00$ & $0,68 \pm 0,01$ \\
\hline Кофеилтартроновая кислота (26) & $21,59 \pm 0,45$ & $21,53 \pm 0,42$ & $12,38 \pm 0,25$ & $20,10 \pm 0,46$ \\
\hline Кафтаровая кислота (27) & $2,10 \pm 0,04$ & $0,89 \pm 0,01$ & $0,67 \pm 0,01$ & $1,67 \pm 0,03$ \\
\hline Цикориевая кислота (28) & $0,40 \pm 0,00$ & $3,12 \pm 0,07$ & $0,30 \pm 0,00$ & $0,14 \pm 0,00$ \\
\hline Фазеловая кислота (29) & $0,78 \pm 0,02$ & $1,06 \pm 0,02$ & $1,92 \pm 0,04$ & $1,62 \pm 0,03$ \\
\hline Розмариновая кислота (30) & $1,18 \pm 0,02$ & $0,15 \pm 0,00$ & $0,49 \pm 0,00$ & $0,70 \pm 0,01$ \\
\hline 3-O-кофеилхинная кислота (31) & $0,27 \pm 0,00$ & $0,41 \pm 0,00$ & $0,48 \pm 0,00$ & $0,59 \pm 0,00$ \\
\hline$\Sigma_{\text {ФлГ }}$ & 2,21 & 0,38 & 8,88 & 3,70 \\
\hline$\Sigma_{\Phi \Pi}$ & 26,76 & 27,47 & 16,60 & 25,50 \\
\hline
\end{tabular}

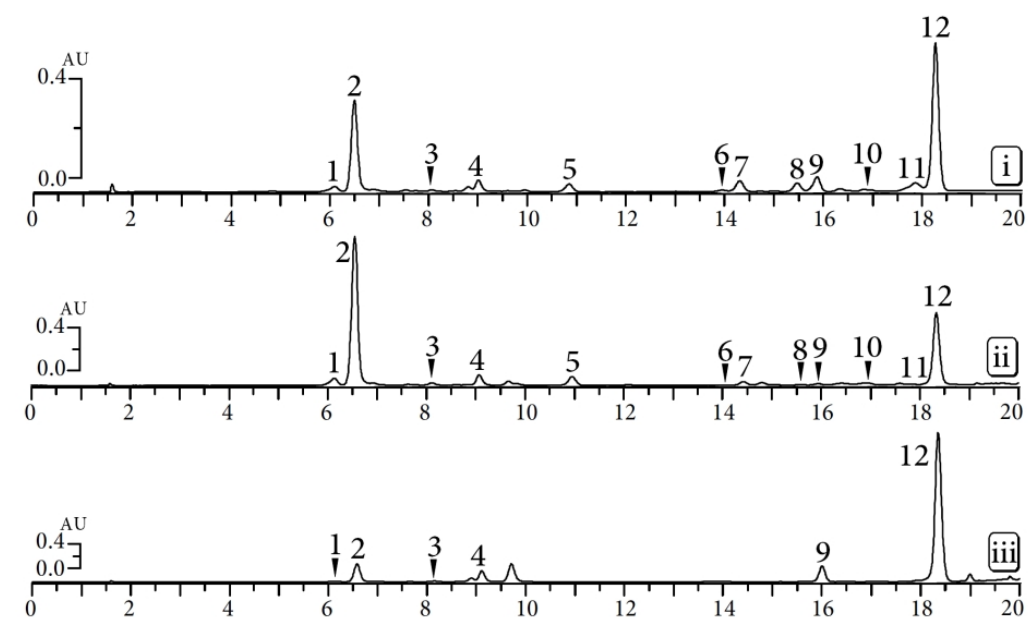

Рис. 3. Хроматограммы (МК-ВЭЖХ-УФ) спиртовых экстрактов из цветков (i), стеблей (ii) и корней N. cataria (iii) при 324 нм (хроматограммы нормированы по основному пику; образец А). Обозначение соединений см. рис. 2

Таблица 2. Содержание флавонгликозидов и фенилпропаноидов в цветках, стеблях и корнях N. cataria, мг/Г возд.-сух. сырья $( \pm S D)$

\begin{tabular}{|c|c|c|c|}
\hline Соединение & Цветки & Стебли & Корни \\
\hline \multicolumn{4}{|c|}{ Флавонгликозиды (ФлГ) } \\
\hline Апигенин-7-O-GlcAp (16) & $1,17 \pm 0,02$ & $<0,01$ & $<0,01$ \\
\hline Апигенин-7-O-Rut (17) & $0,21 \pm 0,00$ & $0,81 \pm 0,01$ & $<0,01$ \\
\hline Лютеолин-7-O-GlcAp (22) & $1,39 \pm 0,03$ & $0,16 \pm 0,00$ & $6,70 \pm 0,14$ \\
\hline Лютеолин-7-O-Rut (23) & $0,84 \pm 0,01$ & $<0,01$ & $<0,01$ \\
\hline Лютеолин-7-O-GlcAp-Glc (24) & $1,08 \pm 0,02$ & $0,88 \pm 0,01$ & $<0,01$ \\
\hline \multicolumn{4}{|c|}{ Фенилпропаноиды (ФП) } \\
\hline Кофейная кислота (25) & $0,45 \pm 0,00$ & $0,98 \pm 0,01$ & $1,84 \pm 0,04$ \\
\hline Кофеилтартроновая кислота (26) & $4,23 \pm 0,09$ & $16,70 \pm 0,36$ & $3,85 \pm 0,08$ \\
\hline Кафтаровая кислота (27) & $0,38 \pm 0,00$ & $1,05 \pm 0,02$ & $0,15 \pm 0,00$ \\
\hline Цикориевая кислота (28) & $0,12 \pm 0,00$ & $0,05 \pm 0,00$ & $<0,01$ \\
\hline Фазеловая кислота (29) & $0,42 \pm 0,00$ & $1,12 \pm 0,02$ & $<0,01$ \\
\hline Розмариновая кислота (30) & $7,67 \pm 0,17$ & $9,39 \pm 0,21$ & $36,93 \pm 0,84$ \\
\hline 3-O-кофеилхинная кислота (31) & $0,15 \pm 0,00$ & $0,39 \pm 0,00$ & $0,22 \pm 0,00$ \\
\hline$\Sigma_{\text {ФлГ }}$ & 4,69 & 1,85 & 6,70 \\
\hline$\Sigma_{\Phi \Pi}$ & 13,42 & 29,68 & 42,99 \\
\hline
\end{tabular}


Содержание фенольных соединений в экстракционных формах N. cataria. Сведения о химическом составе фенольных соединений $N$. cataria указывают на широкую вариабельность их свойств, в частности экстракционной способности в растворителях с отличающейся полярностью. В этой связи для выявления оптимального экстрагента с максимальной извлекающей способностью нами исследованы сухие экстракты, полученные с применением этанола различных концентраций (0-95\%).

Установлено, что использование воды в качестве экстрагента способствовало максимальному выходу конечного продукта (32,1\%) с суммарным содержанием фенольных соединений 50,87 мг/г (табл. 3).

Наибольшее содержание фенольных соединений (94,47-97,76 мг/г) было выявлено в экстрактах, полученных с использованием этанола в диапазоне концентраций 40-70\%. Применение более концентрированного экстрагента приводило к снижению выхода конечного продукта и резко снижало его качество. В качестве оптимального был выбран 40\% этанол, позволяющий получить продукт с наибольшим содержанием целевых соединений.

Таблица 3. Выход и содержание фенольных соединений (ФС) в экстрактах из листьев N. cataria ( $\pm \mathrm{SD})$

\begin{tabular}{|c|c|c|c|c|}
\hline \multirow{2}{*}{ Соединение } & \multicolumn{4}{|c|}{ Концентрация этанола, \% } \\
\hline & 0 & 40 & 70 & 95 \\
\hline Выход, \% & 32,1 & 27,2 & 22,1 & 10,3 \\
\hline Лютеолин-7-O-GlcAp-Glc (24), мг/Г & $0,87 \pm 0,01$ & $1,35 \pm 0,03$ & $0,72 \pm 0,01$ & $0,25 \pm 0,00$ \\
\hline Кофейная кислота (25), мг/г & $0,78 \pm 0,01$ & $1,09 \pm 0,02$ & $1,17 \pm 0,02$ & $0,15 \pm 0,00$ \\
\hline Кофеилтартроновая кислота (26), мг/г & $39,35 \pm 0,91$ & $75,53 \pm 1,73$ & $73,21 \pm 1,70$ & $2,24 \pm 0,05$ \\
\hline Кафтаровая кислота (27), мг/г & $1,20 \pm 0,02$ & $3,12 \pm 0,06$ & $3,67 \pm 0,06$ & $0,00 \pm 0,00$ \\
\hline Цикориевая кислота (28), мг/г & $5,26 \pm 0,12$ & $10,96 \pm 0,25$ & $10,30 \pm 0,24$ & $0,15 \pm 0,00$ \\
\hline Фазеловая кислота (29), мг/г & $2,62 \pm 0,05$ & $3,75 \pm 0,08$ & $3,15 \pm 0,07$ & $0,08 \pm 0,00$ \\
\hline Розмариновая кислота (30), мг/г & $0,10 \pm 0,00$ & $0,51 \pm 0,01$ & $0,63 \pm 0,01$ & $0,55 \pm 0,01$ \\
\hline 3-O-кофеилхинная кислота (31), мг/г & $0,69 \pm 0,01$ & $1,45 \pm 0,03$ & $1,62 \pm 0,03$ & $0,06 \pm 0,00$ \\
\hline$\overline{\Sigma_{\Phi C}}$ & 50,87 & 97,76 & 94,47 & 3,48 \\
\hline
\end{tabular}

Противовоспалительная активность сухого экстракта и некоторых соединений N. сатагіа. Биологическую активность сухого экстракта $N$. cataria изучали в условиях in vivo на модели 12-O-тетрадеканоилфорбол ацетат-индуцированного воспаления уха у мышей. В результате установлено, что в дозе 1 мг/ухо эффективность ингибирования отека экстрактом $N$. cataria была близка к таковой препарата сравнения индометацина в дозе 0,1 мг/ухо (72,1 $\pm 6,2 \%$ в сравнении с контрольной группой) и составила $63,4 \pm 3,6 \%$. Дополнительно была определена эффективность двух доминирующих соединений - лютеолин-7-O-(6"-глюкуроно)-глюкозида (24) и кофеилтартроновой кислоты (26), ранее не исследовавшихся на наличие биологической активности. Эксперименты показали, что применение 26 в дозе 0,1 мг/г приводило к формированию выраженного противовоспалительного эффекта $(68,4 \pm 6,0 \%)$, в то время как 24 в аналогичной дозе оказался менее эффективным (50,3 $\pm 3,2 \%)$. Таким образом, можно предположить, что противовоспалительные свойства у препаратов $N$. cataria обусловлены наличием в нем фенилпропаноидов, в частности высоким содержанием 26.

\section{Выводы}

Проведенные исследования показали, что в условиях Восточной Сибири возможна интродукция N. cataria, позволяющая получать растительное сырье удовлетворительного качества с высоким содержанием биологически активных фенольных соединений. Химическое изучение $N$. cataria позволило подтвердить наличие в нем редкой ацилальдаровой кислоты - кофеилтартроновой кислоты (26), обнаруженной кроме N. cataria [2] только в трех растительных видах - Chondrilla juncea L. (Asteraceae) [21], Parthenocissus tricuspidata (Siebold \& Zucc.) Planch. (Vitaceae) [22] и Echinodorus macrophyllus (Kunth) Micheli (Alismataceae) [23]. Помимо 26, также выявлено присутствие кофеилтетраровых (кофеилвинных) кислот - кафтаровой и цикориевой, что подтверждает существование биосинтетических возможностей для продукции данной группы соединений. Особый интерес вызывает факт присутствия в N. cataria гликозидированных производных акацетина, которые, по утверждению Z. Jamzad c coaвт. [5], не являются типичными представителями семейства фенолов для рода Nepeta L. в целом. Вероятной причиной этого может быть влияние экологических условий произрастания растительного организма на течение процессов биосинтеза флавоноидов. Согласно сведениям о количественном содержании отдельных соединений, фенил- 
пропаноиды - это основная группа фенольных соединений $N$. cataria, содержание которой может составлять 1,7-2,8\% от массы растительного сырья. Данный факт необходимо учитывать при создании системы контроля качества сырья $N$. cataria, тем более, что в результате наших исследований выявлено, что фенилпропаноиды можно рассматривать в качестве действующей группы соединений.

\section{Сиисок литературы}

1. Formisano C., Rigano D., Senatore F. Chemical constituents and biological activities of Nepeta species // Chem. Biodiv. 2011. Vol. 8. Pp. 1783-1818.

2. Snook M.E., Blum M.S., Whitman D.W., Arrendale R.F., Costello C.E., Harwood J.S. Caffeoyltartartronic acid from catnip (Nepeta cataria): A precursor for catechol in lubber grasshopper (Romalea guttata) defensive secretions // J. Chem. Ecol. 1993. Vol. 19. Pp. 1957-1966.

3. Mišić D., Šiler B., Gašić U., Avramov S., Živković S., Živković J.N., Milutinović M., Tešić Z. Simultaneous UHPLC/DAD/(+/-)HESI-MS/MS analysis of phenolic acids and nepetalactones in methanol extracts of Nepeta species: A possible application in chemotaxonomic studies // Phytochem. Anal. 2015. Vol. 26. Pp. 72-85.

4. Modnicki D., Tokar M., Klimek B. Flavonoids and phenolic acids of Nepeta cataria L. var. citriodora (Becker) Balb. (Lamiaceae) // Acta Polon. Pharm. 2007. Vol. 64. Pp. 247-252.

5. Jamzad Z., Grayer R.J., Kite G.C., Simmonds M.S.J., Ingrouille M., Jalili A. Leaf surface flavonoids in Iranian species of Nepeta (Lamiaceae) and some related genera // Biochem. Syst. Ecol. 2003. Vol. 31. Pp. 587-600.

6. Ricci E.L., Toyama D.O., Lago J.H.G., Romoff P., Kirsten T.B., Reis-Silva T.M., Bernard M.M. Anti-nociceptive and anti-inflammatory actions of Nepeta cataria L. var. citriodora (Becker) Balb. essential oil in mice // J. Health Sci. Inst. 2010. Vol. 28. Pp. 289-293.

7. Olennikov D.N., Kashchenko N.I., Chirikova N.K., Koryakina L.P., Vladimirov L.N. Bitter gentian teas: Nutritional and phytochemical profiles, polysaccharide characterisation and bioactivity // Molecules. 2015. Vol. 20. Pp. 20014-20030.

8. Ayatollahi S.A., Shojaii A., Kobarfard F., Mohammadzadeh M., Choudhary M.I. Two flavones from Salvia leriaefolia // Iran. J. Pharm. Res. 2009. Vol. 8. Pp. 179-184.

9. Alwahsh M.A.A., Khairuddean M., Chong W.K. Chemical constituents and antioxidant activity of Teucrium barbeyanum Aschers. // Rec. Nat. Prod. 2015. Vol. 9. Pp. 159-163.

10. Farjam M.H., Rustaiyan A., Ezzatzadeh E., Jassbi A.R. Labdane-type diterpene and two flavones from Salvia sharifii Rech. f. Esfan. and their biological activities // Iran. J. Pharm. Res. 2013. Vol. 12. Pp. 395-400.

11. Ferreres F., Barberan F.A.T., Tomas F. 5,6,4'-Trihydroxy-7,8-dimethoxyflavone from Thymus membranaceus // Phytochemistry. 1985. Vol. 24. Pp. 1869-1871.

12. Wollenweber E., Dörr M., Rivera D., Roitman J.N. Externally accumulated flavonoids in three Mediterranean Ononis species // Z. Naturforsch. 2003. Vol. 58 c. Pp. 771-775.

13. Iinuma M., Matsuura S., Kurogochi K., Tanaka T. Studies on the constituents of useful plants. V. Multisubstituted flavones in the fruit peel of Citrus reticulata and their examination by gas-liquid chromatography // Chem. Pharm. Bull. 1980. Vol. 28. Pp. 717-722.

14. Barberan F.A.T., Ferreres F., Tomas F. TLC, UV and acidic treatment in the differentiation of 5,6- and 5,8dihydroxyflavones, 3-methoxyflavones and flavonols // Tetraherdon. 1985. Vol. 41. Pp. 5733-5740.

15. Iwashina T., Kokubugata G. Flavone and flavonol glycosides from the leaves of Triumfetta procimbens in Ryukyu Islands // Bull. Natl. Mus. Nat. Sci. 2012. Vol. 38. Pp. 63-67.

16. Bourwieg D., Pohl R. Die Flavonoide von Mentha longifolia // Planta Med. 1973. Vol. 24. Pp. 304-314.

17. Zakharova O.I., Zakharov A.M., Glyzin V.I. Flavonoids of Agastache rugosa // Chem. Nat. Comp. 1979. Vol. 15. Pp. 561-564.

18. Nuissier G., Rezzonico B., Grignon-Dubois M. Chicoric acid from Syringodium filiforme // Food Chem. 2010. Vol. 120. Pp. 783-788.

19. Satake T., Kamiya K., Saiki Y., Hama T., Fujimoto Y., Kitanaka S., Kimura Y., Uzawa J., Endang H., Umar M. Studies on the constituents of Helicteres isora L. // Chem. Pharm. Bull. 1999. Vol. 47. Pp. 1444-1447.

20. Olennikov D.N., Stolbikova A.V., Tankhaeva L.M., Petrov E.V. Phenylpropanoids and polysaccharides of Plantago depressa and P. media // Chem. Nat. Comp. 2011. Vol. 47. Pp. 165-169.

21. Terencio M.C., Giner R.M., Sanz M.J., Máñez S.M., Ríos J.L. On the occurrence of caffeoyltartronic acid and other phenolics in Chondrilla juncea // Z. Naturforsch. 1993. Vol. 48c. Pp. 417-419.

22. Saleem M., Hyoung J.K., Jin C., Yong S.L. Antioxidant caffeic acid derivatives from leaves of Parthenocissus tricuspidata // Arch. Pharm. Res. 2004. Vol. 27. Pp. 300-304.

23. Silva T.M., Dias M.D., Pereira M.T., Piló-Veloso D., Alcântara A.F.C. Effect of the $\gamma$-radiation on phenol fractions obtained from the leaves of Echinodorus macrophyllus Mich. // Rad. Phys. Chem. 2012. Vol. 81. Pp. 22-26.

Поступило в редакиию 28 января 2016 г. 
Kashchenko N.I., Olennikov D.N. ${ }^{*}$ CHEMICAL PROFILE AND BIOLOGOCAL ACTITITY OF FLAVONOIDS AND PHENYLPROPANOIDS FROM NEPETA CATARIA L. (LAMIACEAE) CULTIVATED IN THE EASTERN SIBERIA

Institute of General and Experimental Biology, Siberian Branch, Russian Academy of Science, 6 Sakh yanovoy Street, Ulan-Ude,670047 (Russia),e-mail: olennikovdn@mail.ru

A chemical investigation of Nepeta cataria L. (Lamiaceae), cultivated in the Eastern Siberia (Buryatia Republic, Russia) was realized. Thirty-one compounds were isolated using different chromatographic techniques including components detected in species for the first time: chrisoeriol, cirsilineol, isorhoifolin, tilianin, acacetin-7-O-glucuronide, linarin, scolimoside, caftaric, cichoric and phaselic acids. In the course of studying the distribution of phenolic compounds in organs of $N$. cataria it was shown first that the accumulation of compounds was characterized by the organ specific manner. Caffeoyltartronic acid was a dominant compound in leaves $\left(21,59 \mathrm{mg} \cdot \mathrm{g}^{-1}\right)$ and stems $\left(16.70 \mathrm{mg} \cdot \mathrm{g}^{-1}\right)$, as well as rosmarinic acid dominated in roots $\left(36,93 \mathrm{mg} \cdot \mathrm{g}^{-1}\right)$ and flowers $\left(7,67 \mathrm{mg} \cdot \mathrm{g}^{-1}\right)$. The investigation of the biological activity of $N$. cataria dry extract showed the presence of anti-inflammatory properties. For the first time the anti-inflammatory activity of two marker compounds of $N$. cataria like luteolin-7-O-(6"-glucurono)-glucoside and caffeyltartronic acid was revealed, and the efficiency of the latter compound was the highest.

Keywords: Nepeta cataria L., Lamiaceae, flavonoids, phenylpropanoids, caffeoyltartronic acid, HPLC, antiinflammatory activity.

\section{References}

1. Formisano C., Rigano D., Senatore F. Chem. Biodiv., 2011, vol. 8, pp. 1783-1818.

2. Snook M.E., Blum M.S., Whitman D.W., Arrendale R.F., Costello C.E., Harwood J.S. J. Chem. Ecol., 1993, vol. 19, pp. 1957-1966.

3. Mišić D., Šiler B., Gašić U., Avramov S., Živković S., Živković J.N., Milutinović M., Tešić Z. Phytochem. Anal., 2015, vol. 26, pp. 72-85.

4. Modnicki D., Tokar M., Klimek B. Acta Polon. Pharm., 2007, vol. 64, pp. 247-252.

5. Jamzad Z., Grayer R.J., Kite G.C., Simmonds M.S.J., Ingrouille M., Jalili A. Biochem. Syst. Ecol., 2003, vol. 31, pp. 587-600.

6. Ricci E.L., Toyama D.O., Lago J.H.G., Romoff P., Kirsten T.B., Reis-Silva T.M., Bernard M.M. J. Health Sci. Inst., 2010, vol. 28, pp. 289-293.

7. Olennikov D.N., Kashchenko N.I., Chirikova N.K., Koryakina L.P., Vladimirov L.N. Molecules, 2015, vol. 20, pp. 20014-20030.

8. Ayatollahi S.A., Shojaii A., Kobarfard F., Mohammadzadeh M., Choudhary M.I. Iran. J. Pharm. Res., 2009, vol. 8, pp. 179-184.

9. Alwahsh M.A.A., Khairuddean M., Chong W.K. Rec. Nat. Prod., 2015, vol. 9, pp. 159-163.

10. Farjam M.H., Rustaiyan A., Ezzatzadeh E., Jassbi A.R. Iran. J. Pharm. Res., 2013, vol. 12, pp. 395-400.

11. Ferreres F., Barberan F.A.T., Tomas F. Phytochemistry, 1985, vol. 24, pp. 1869-1871.

12. Wollenweber E., Dörr M., Rivera D., Roitman J.N. Z. Naturforsch., 2003, vol. 58c, pp. 771-775.

13. Iinuma M., Matsuura S., Kurogochi K., Tanaka T. Chem. Pharm. Bull., 1980, vol. 28, pp. 717-722.

14. Barberan F.A.T., Ferreres F., Tomas F. Tetraherdon, 1985, vol. 41, pp. 5733-5740.

15. Iwashina T., Kokubugata G. Bull. Natl. Mus. Nat. Sci., 2012, vol. 38, pp. 63-67.

16. Bourwieg D., Pohl R. Planta Med., 1973, vol. 24, pp. 304-314.

17. Zakharova O.I., Zakharov A.M., Glyzin V.I. Chem. Nat. Comp., 1979, vol. 15. Pp. 561-564.

18. Nuissier G., Rezzonico B., Grignon-Dubois M. Food Chem., 2010. Vol. 120, pp. 783-788.

19. Satake T., Kamiya K., Saiki Y., Hama T., Fujimoto Y., Kitanaka S., Kimura Y., Uzawa J., Endang H., Umar M. Chem. Pharm. Bull., 1999, vol. 47, pp. 1444-1447.

20. Olennikov D.N., Stolbikova A.V., Tankhaeva L.M., Petrov E.V. Chem. Nat. Comp., 2011, vol. 47, pp. $165-169$.

21. Terencio M.C., Giner R.M., Sanz M.J., Máñez S.M., Ríos J.L. Z. Naturforsch., 1993, vol. 48c, pp. 417-419.

22. Saleem M., Hyoung J.K., Jin C., Yong S.L. Arch. Pharm. Res., 2004, vol. 27, pp. 300-304.

23. Silva T.M., Dias M.D., Pereira M.T., Piló-Veloso D., Alcântara A.F.C. Rad. Phys. Chem., 2012, vol. 81, pp. $22-26$.

Received January 28, 2015

Revised February 20, 2016

\footnotetext{
* Corresponding author.
} 